\title{
AS FRENTES DE EXPANSÃO NAS FRONTEIRAS DO ALTO MADEIRA (1867-1915)
}

\author{
THE EXPANSION FRONTS AT THE BORDERS OF ALTO MADEIRA
}

(1867-1915)

Jorge de Oliveira Campos'

\begin{abstract}
Resumo
O presente trabalho tem como objetivo analisar a situação das fronteiras do Alto Madeira, entre os anos de 1867 a 1915, a fim de evidenciar nessa região limítrofe entre Brasil e Bolívia, as interações conflitivas entre povos nativos e as frentes de expansão extrativista e ferroviária. Assim, procuramos corroborar com estudos sobre à formação das fronteiras Sul-americanas, bem como evidenciar os desdobramentos acerca dos movimentos expansionistas em territórios indígenas. Este estudo, parte de uma leitura crítica das fontes históricas documentais, tais como: relatórios oficiais, periódicos locais, tratados de limites territoriais, e das literaturas de época.
\end{abstract}

Palavras-chave: Fronteiras; Alto Madeira; interações conflitivas; indígenas.

\begin{abstract}
This paper aims to analyze the situation of the borders of Alto Madeira between the years 1866 to 1913, in order to show in this bordering region between Brazil and Bolivia, the conflicting interactions between native peoples and the fronts of extractive and railway expansion. Thus, we seek to corroborate with studies on the formation of South American borders, as well as to evidence the developments regarding expansionist movements in indigenous territories. This study is based on a critical reading of historical documentary sources, such as: official reports, local periodicals, treaties on territorial limits, and period literature.
\end{abstract}

Keywords: Frontiers; Alto Madeira; conflicting interactions; indigenous.

\footnotetext{
${ }^{1}$ Possui graduação em História pela Universidade do Estado do Amazonas - UEA (2015), é mestre em história social pela Universidade Federal do Amazonas - UFAM (2019). Atualmente, trabalha como professor de história pela Secretaria Municipal de Educação de Manaus - SEMED lecionando em turmas do Ensino Fundamental Anos Finais. Também é professor de mediação tecnológica pela Secretaria de Educação do Estado do Amazonas - SEDUC. E-mail: jorge_campos182@ hotmail.com
} 


\section{Introdução}

Os limites territoriais do Alto Madeira (atual território de Rondônia e circunvizinhanças), constituiu-se segundo a história diplomática, por tratados e decretos acordados entre os Estados Modernos, Brasil e Bolívia. Acordos estes que foram sendo estabelecidos desde a segunda metade do século XIX até a primeira década do século XX. Assim, os movimentos de expansão fronteiriças que corroboraram com as demarcações e limites territoriais do Brasil, na Amazônia, não estavam vinculados apenas na colonização e na posse definitiva de território, mas também na procura por recursos naturais, e nesses casos, os movimentos se baseavam quase sempre, em incursões ou expedições exploratórias. $^{2}$

Todavia, esses processos de expansão fronteiriças, não consideraram critérios que avaliassem os impactos que causariam aos povos nativos. Neste sentido, os encontros culturais entre os povos originários e os grupos advindos com os movimentos das frentes de expansão extrativista e da frente ferroviária para o Alto Madeira, foram elencados no presente trabalho, a fim de perceber as diversas formas de interações, tanto no âmbito do intercâmbio cultural, quanto nas relações interétnicas e socioculturais, e que na maioria delas, baseavam-se em encontros e interações conflitivas.

Para a análise dessa região fronteiriça, desenvolvi à problemática das interações culturais conflitantes, a partir das teorias da etnicidade, em convergência com a perspectiva de que, "a etnicidade implica sempre na organização de agrupamentos dicotômicos Nós/Eles. Assim, a etnicidade "não pode ser concebida senão na fronteira do "Nós", em contato ou confrontação, ou por contraste com "Eles" procuramos evidenciar as identidades étnicas e pertenças indígenas, além de construir narrativas descolonizadoras, de modo a representar a luta dos povos indígenas que de certa forma sofreram no decorrer das dinâmicas de expansão das fronteiras dos Estados Nacionais na América do Sul.

De acordo com o sociólogo José de Souza Martins, é na fronteira que puderam coexistir diferentes grupos sociais e étnicos que travaram disputas em prol de interesses conflitantes. Assim como nas situações de historicidades desencontradas, ou seja, as

\footnotetext{
${ }^{2}$ VELHO, Otávio Guilherme. Frentes de expansão e estrutura agrária: estudo do processo de penetração numa área da Transamazônica. Rio de Janeiro: Centro Edelstein de Pesquisas Sociais, 2009, p. 6.

${ }^{3}$ POUTIGNAT, Philippe. Teorias da etnicidade. Seguido de Grupos étnicos e suas fronteiras de Fredrik Barth. São Paulo: Fundação Editora UNESP, tradução de Elcio Fernandes, 1998, p. 153.
} 
fronteiras podem ser além de conflitivas, um elemento de disputas por projetos históricos de distintas versões. Neste sentido, a fronteira é um ponto limite de território que é continuamente disputado de diferentes modos e por diferentes grupos sociais criando assim uma multiplicidade de fronteiras. ${ }^{4}$

Neste sentido, ao pensarmos os sistemas de valores engendrados no pensamento social dos sujeitos que compunham as frentes de expansão no Madeira, assim como os meios de comunicação que os informavam, os quais descreviam os índios em um contexto de barbárie e selvageria. Estas concepções vindas de fora, em especial as visões acerca da relação das frentes de expansão no Madeira com os índios Kawahíwa-Parintintin, estes últimos que pertencem ao tronco linguístico dos Tupi Centrais, e que no percurso da história reivindicaram suas terras ancestrais imemoriais no Madeira há mais de um século, foi uma das etnias que sobreviveu ao processo de expansão fronteiriça. ${ }^{5}$

Essas visões de fora, que propagaram os seus costumes, as ações e modos de vida indígena, formuladas por grupos que atravessaram as fronteiras, rios, florestas e interpretaram esses nativos a partir dos seus interesses, seus valores e crenças, refletiu-se na construção de uma simbologia da violência, o que culminou com uma investigação densa no presente trabalho das problemáticas acerca dos territórios fronteiriços do Alto Madeira.

Por outro lado, outras conexões por meio da mobilidade nos rios no século XIX e dos trabalhos nos trilhos nas selvas amazônicas até as primeiras décadas do século XX, alavancariam expedições vindas da Bolívia e Peru, desde trabalhadores em rotas em direção aos grandes polos da floresta amazônica, bem como expedições más intencionadas à procura de redenção e lucratividade com a extração e exploração dos recursos naturais nas densas florestas situadas em territórios indígenas.

Nessas territorialidades investigadas, marcadas por conflitos antagônicos e contrastes entre culturas nativas e as oriundas de fora, em meio a alteridade, os povos indígenas eram classificados com roupagens de "barbárie e selvageria". Essas formas de classificar ou construir categorias que desqualificassem os povos indígenas, seriam medidas de subjugá-los e de traçar uma política governamental de dominação advinda com as frentes de expansão?

\footnotetext{
${ }^{4}$ MARTINS, José de Souza. Fronteira: a degradação do outro nos confins do humano. São Paulo: Contexto, $2^{\mathrm{a}}$. Ed., 2018, p.10.

${ }^{5}$ CAMPOS, Jorge de Oliveira. Caminhos da Guerra: os índios Parintintin e as frentes de expansão seringalista no rio Madeira (1853 - 1923). Dissertação, (Mestrado em História), Instituto de Filosofia, Ciências Humanas e Sociais, Universidade Federal do Amazonas, 2019.
} 
Segundo o historiador Benedict Anderson, "dependendo dos interesses dominantes, as categorias censitárias poderiam constantemente ser unificadas, separadas, recombinadas, misturadas e reordenadas". ${ }^{6}$ De acordo com Foeraker, referido no livro, La frontera domesticada, escrito por Santos-Granero e Barclay, o autor construiu um interessante panorama geral sobre o avanço das fronteiras pioneiras na Amazônia brasileira, e considerou que o processo de integração de formas de produção précapitalista às formas capitalistas de produção, estão imbricadas em uma transformação que não se produz sem oposição, ou seja, porquê a luta por território e o controle da força de trabalho que enfrentam as populações locais, os migrantes e imigrantes, advindas de forças contrárias, referindo-se as empreiteiras e companhias poderosas, que alimentam o processo de expansão da fronteira. Revelou-se ser uma problemática no qual ele definiu como sendo, el drama de la frontera. ${ }^{7}$

\section{Fronteiras: Brasil, Peru e Bolívia e as dinâmicas de fluxos no Alto Madeira}

Em meados século XIX, a questão da navegação no rio Madeira, em ligar pontos distantes da grande bacia fluvial amazônica, estava muito atrelada aos acordos diplomáticos acerca dos limites territoriais fronteiriços, ainda mal definidos entre Brasil e as repúblicas ribeirinhas, Peru e Bolívia. Na disputa pelo território do Alto Madeira, esses países ainda teriam como parâmetros para resolver as suas intrincadas relações diplomáticas por território, os antigos Tratado de Madri, de 1750, e o Tratado de Santo Idelfonso, de 1777.

Recuando para esse recorte histórico de tratativas diplomáticas, percebeu-se que as disputas territoriais entre esses países fronteiriços sul-americanos, vinham ocorrendo desde o período em que o Brasil era governado por um sistema colonial português mercantilista, assim como o Peru, que nesse período mencionado ainda era administrado por um sistema colonial hispano-americano. Nesse contexto colonial luso-hispânico na Amazônia, a disputa pelo território fronteiriço do Alto Madeira, era reivindicado pela diplomacia luso-brasileira, pelo princípio romano regulador do uti possidetis (posse real e efetiva), isso quer dizer, que a terra pertenceria a quem à ocupasse ${ }^{8}$.

\footnotetext{
${ }^{6}$ ANDERSON, Benedict. Censo, mapa, museu. In: Comunidades imaginadas: reflexões sobre a origem e a difusão do nacionalismo. São Paulo: Companhia das Letras, tradução, Denise Bottman, 2008, p. 226.

7 SANTOS-GRANERO, Fernando; BARCLAY, Frederica. La frontera Domesticada: História econômica y social de Loreto, 1850 - 2000. Perú: Fondo editorial. 2002, p.18.

${ }^{8}$ Ver em: SOTOMAYOR, Walter Auad. Relações Brasil Bolívia: a definição das fronteiras. Brasília: Verbena Editora, 2018, p. 51; MELLO, Mauro Pereira de. A questão de limites entre os Estados do Acre, do Amazonas e de Rondônia (Aspectos Históricos e Formação de Território). Revista Brasileira de
} 
Enquanto isso, a república peruana ainda se amparava pelo Tratado de Santo Idelfonso, pois esse tratado postulava ao Peru, o direito a uma dimensão territorial nos moldes coloniais, "uma vez que o Peru pregava que sua fronteira com o Brasil deveria ser dada pela linha média entre os rios Madeira e Javari, o que aumentava sua extensão territorial." $" 9$ Dessa forma, dava seguimento ao pleito de incursões predatórias e de ocupação por grupos de caucheiros peruanos na zona litigiosa (atual Estado do Acre), também expandiu-se para outras zonas, como as áreas abaixo das cachoeiras do rio Madeira e de seus afluentes. ${ }^{10}$

Assim, esses impasses diplomáticos entre estas duas nações continuariam a se prologar por toda a primeira metade do século XIX, no qual a influência da diplomacia imperial brasileira, sob égide do "uti possidetis constituiria o pacote ideológico ideal para justificar a própria dinâmica do sistema expansionista de conquistas fronteiriças" ${ }^{11}$. Nesta perspectiva, outras tratativas foram sendo tecidas para contornar as relações diplomáticas do Império do Brasil com as repúblicas ribeirinhas. De acordo com a historiadora Nicia Vilela Cruz, sobre esses processos diplomáticos nas fronteiras do Madeira, destaca que:

[...], a Bolívia entrou na disputa por uma via independente, em que ignorou a posição brasileira, pois buscou contar com o apoio de potências estrangeiras, principalmente da França e dos Estados Unidos, para levar avante seus propósitos de atingir o Amazonas e navegá-lo. Através do Cônsul boliviano, Pazos Kanti, no ano de 1844, contrata com o governo francês, a navegação dos rios daquela república. Não indo a frente esse acordo do governo boliviano com a França; um ano depois, o governo da Bolívia, impaciente por não ter concretizado seus desejos de mobilidade nos rios brasileiros, ordenou que uma forquilha de 15 canoas e lanchas sob o comando de um tenente coronel boliviano, baixasse o Madeira para cuidar e obter o consentimento prévio do Brasil. ${ }^{12}$

\section{A questão da navegabilidade e comércio boliviano pelas fronteiras do Alto Madeira}

A busca do governo boliviano em estabelecer relações diplomática com Brasil, perpassava pelas questões navegabilidade e comércio, principalmente no que se refere ao

\footnotetext{
Geografia. Rio de Janeiro, Fundação Instituto Brasileiro de Geografia e Estatística, 1990, v. 52, n.4, pp. 7 $-71$.

${ }^{9}$ PONTES, Kassius Dinis da Silva. Euclides da Cunha, o Itamaraty e a Amazônia. Brasília: Funag, 2005 , p. 124.

10 “A noção de zona também pode se referir a áreas não permanentes: a zona de contaminação, ou zona de conflito, praticamente sinônimo de área de contaminação e área de conflito, podendo recobrir secções transversais de regiões diversas." BARROS, José D’Assunção. História, Espaço, Geografia: diálogos interdisciplinares. Petrópolis, RJ: Vozes, 2017, p. 49.

${ }^{11}$ GOES FILHO, Synesio Sampaio. As Fronteiras do Brasil. Brasília: Funag, 2013, p. 27.

${ }^{12}$ LUZ, Nicia Vilela. A política amazônica das repúblicas ribeirinhas e a diplomacia continental. In: A Amazônia para os negros americanos. Rio de Janeiro: Editora Saga, 1968, p. 130, 131.
} 
escoamento da produção boliviana pelo território e águas brasileiras. Anterior a essas relações, precisamos entender que, "Peru e Bolívia, antes de se constituírem países independentes, faziam parte do território de Charcas ou Alto Perú, na América Espanhola". 13

Após a independência boliviana, em 1825, esse país passou a ser desfavorecido em rotas de acesso ao mar, motivo este que ocorreu através de inúmeras guerras ao longo de mais de uma década, mas que isso acabou levando esse país a se tornar uma república. O processo de independência boliviana culminou com a separação do Peru, o que implicaria na divisão dos territórios e a perda parcial do acesso ao Oceano Pacífico, o que deixou os bolivianos com poucas rotas comerciais em direção ao Pacífico.

Assim, uma das rotas comerciais bolivianas que passava pelo território peruano, era navegável pelo Lago Titicaca ou o contornavam, chegando em Puno na margem daquele lago, tinham que descer as Cordilheiras do Andes para irem negociar seus produtos em portos tradicionais como o de Arica ou Molendo. Existia também, o caminho inteiramente através de território boliviano, no qual pelo Altiplano desciam as escarpas do Andes, ganhava-se as planícies costeiras, atravessando o extenso deserto do Atacama onde não havia água, até chegar em Cobija. Este transporte era feito por mulas, o que dificultaria o transporte de cargas pesadas. ${ }^{14}$

Essa problemática resultaria para os bolivianos acionar outros percursos comerciais que facilitassem a mobilidade e trânsito comercial, e nisso, as vias fluviais como, os rios Madre de Dios, Beni e Mamoré, que desaguavam no rio Madeira, possibilitariam assim, ter percursos mais eficientes em transportar suas mercadorias para mercados internacionais, navegando pelos rios Madeira e Amazonas até o Atlântico. A partir desse oceano podia-se alcançar outros centros consumidores de seus produtos primários, como os Estados Unidos e a Europa. Outro fator que dificultaria a comercialização da Bolívia com o mercado externo era "o problema da solução da navegação nos trechos encachoeirados dos rios Madeira e Mamoré"15. O que, de certa forma dificultava o escoamento de produtos naturais vindos das terras baixas bolivianas, como a borracha, e o seu transporte em larga escala.

Mesmo com esses percalços, os mercadores bolivianos se arriscavam descendo o Altiplano andino em meados do século XIX para navegarem por rio tortuosos em direção

\footnotetext{
${ }^{13}$ FERREIRA, Manoel Rodrigues. A ferrovia do diabo. São Paulo: Melhoramentos. 1960, p. 67.

${ }^{14}$ FERREIRA, Manoel Rodrigues. A ferrovia do diabo, pp. $67-71$.

${ }^{15}$ FERREIRA, Manoel Rodrigues. A ferrovia do diabo, p. 12.
} 
ao tributário do Amazonas, o rio Madeira. Esses mercadores que bem antes da chegada da modernidade trazida pelos trilhos da Estrada de Ferro Madeira-Mamoré, se destacavam como exímios navegadores, e por terem destreza e capacidade de evitar os ataques de índios hostis.

Segundo Tavares Bastos, em seu livro, O Vale do Amazonas, relata as proezas dos mercadores bolivianos em navegar em rios da Bacia Amazônia, repletos de corredeiras e cachoeiras, como a costumeira navegação no rio Madeira.

Os bolivianos, descendo pelo Madeira, deixam em Serpa [Itacoatiara] nas suas canoas (ubás, construídas as vezes de um só tronco). E descem nos paquetes até ao Pará, onde vendem o cacau, o fumo, couros e outros produtos, e compram os objetos de que carecem (ferro em vergas, machados, instrumentos agrícolas, pólvora, espingardas, licores, quinquilharias, etc.). A viagem de retorno, nas canoas, é penosíssima; exige as vezes três meses e mais. ${ }^{16}$

O comércio entre localidades extremas, incentivava as conexões e limites culturais fluídos que favoreciam os intercâmbios culturais, e nessa persistência em permear caminhos tortuosos e cheios de obstáculos, quebram a ideia de barreiras naturais e limites intransponíveis imaginados pelo homem moderno. As formas de negociações que envolviam os bolivianos, que se deslocavam da região do altiplano para negociar seus produtos naturais e artesanais em troca de produtos industrializados em território brasileiro, nesse trânsito entre fronteiras também foi percebida a presença de bolivianos na prestação de serviços em obras públicas na capital Manaus.

Assim como, esses negociadores vindos da Bolívia, por volta de 1866, percorriam rotas comerciais, levando mercadorias da Bolívia a grandes centros mercantis brasileiros, como o mercado do Ver-o-Peso na província do Pará ${ }^{17}$. Em direção a esses lugares, os úbas eram meios de navegações eficientes no percurso do rio Madeira até sua foz, pela interessante capacidade de transpor os trechos encachoeirados do Alto rio Madeira, e levar as mercadorias e os produtos valiosíssimos que se tornaram ambicionados nos mercados nacionais brasileiros e internacionais, como o látex de alta qualidade produzido na região boliviana, no tentando essas mercadorias eram transportadas a nível parcos, e não supria a demanda internacional pelo látex.

\footnotetext{
16 BASTOS, Aureliano Cândido Tavares. O vale do Amazonas: A livre navegação do Amazonas, estatística, producções, commercio, questões ficaes do Valle do Amazonas. São Paulo: Companhia Editora Nacional, 2. ed., 1937, p. 222, 223.

${ }^{17}$ CALDAS, Sérgio Túlio. Portos do Brasil = The Ports of Brazil. São Paulo: Horizonte, 2008.
} 


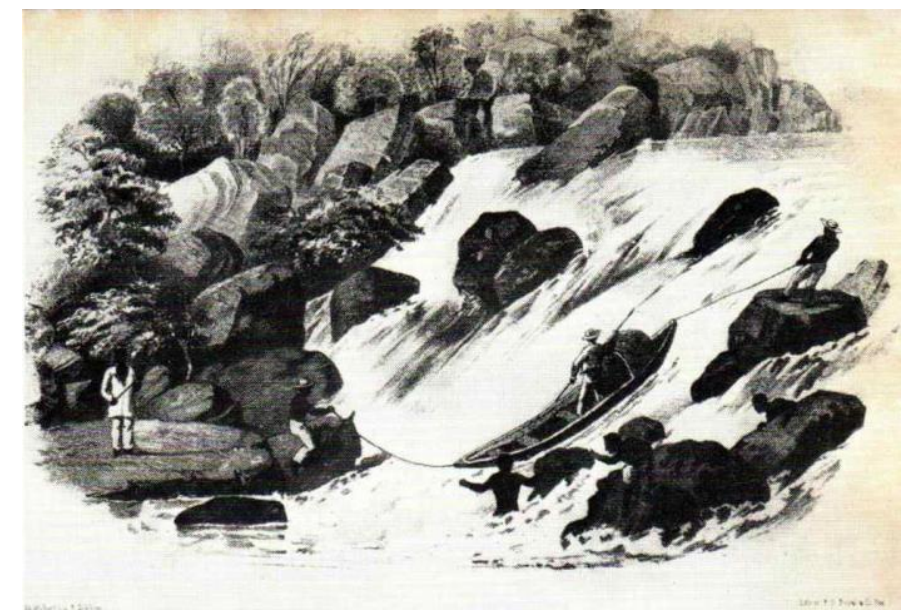

Imagem 1: Cachoeira do Ribeirão, rio Madeira. ${ }^{18}$

De acordo com Tavares Bastos, essas embarcações bolivianas, eram tripulados por índios do Beni, no qual ele descreve como "gente dócil e dedicada ao serviço, sóbrios, ligeiramente vestidos de uma curiosa camisola feita de casca da palmeira, homens válidos, quais os vi em Manaus”. Segundo ainda este autor, esses numerosos e robustos índios bolivianos do departamento do Beni, dos quais tripulavam as canoas do Madeira, ficavam nos intervalos das viagens trabalhando nas obras públicas de Manaus em troca de um salário módico ou de algumas roupas, armas e tecidos que bastavam para atrair outros. ${ }^{19}$

Esses mercadores bolivianos indígenas que exerciam uma parcela de trabalhadores nas obras públicas da capital da Província do Amazonas, vinham de regiões vizinhas as antigas missões religiosas de Moxos e Chiquitos, e que por conta disso eram considerados disciplinados, pois as suas experiências no trabalho nos aldeamentos missionários, os prepararam para os ritmos laborais e a vida sedentária, em outras palavras para a "civilização". O despovoamento das missões de Moxos e Chiquitos teve como causas, as recorrentes migrações para as regiões gomíferas do Brasil e na Bolívia, pelo fato da exploração da goma elástica nas zonas gomíferas brasileiras e o descobrimento da goma elástica no departamento boliviano do Beni, motivou demandas por mão de obra

\footnotetext{
${ }^{18}$ Cachoeira de Ribeirão, uma das várias cachoeiras no alto rio Madeira, percebe-se a dificuldade de acesso à região fronteiriça do Brasil com a Bolívia. A figura representa uma embarcação igarité ou úba, é sustentada na descida, por um homem que segura uma corda, nas pedras um tripulante e dentro d'água alguns índios bolivianos e escravos africanos responsáveis pelo transporte das mercadorias. Gravura do livro de Herndon e Gibbon, de 1851. FERREIRA, Manoel Rodrigues. 1959, p. 47.

${ }^{19}$ BASTOS, Aureliano Cândido Tavares. Mamoré, Guaporé, Madeira. In: O Vale do Amazonas, pp. $315-$ 317.
} 
para exploração gomífera e seu transporte. ${ }^{20}$ Outros motivos dos despovoamentos, estavam relacionados com a fundação dessas missões, como o exemplo das missões em Chiquitos, que "foram formadas também com a "escravização" de índios [bororo] da região [...], o que não era raro desertarem para o Brasil." 21

As questões de navegabilidade nas fronteiras entre Brasil com a Bolívia, em aproximar as relações de comércio e indústria extrativa, em fronteiras transnacionais, vinculadas com a migração de trabalhadores para a exploração da borracha e para as obras públicas na capital da Província do Amazonas e Província do Mato Grosso, fortaleceram a política diplomática de incentivo à abertura da navegabilidade no rio Madeira para nações amigas estrangeiras, o que veio a se estabelecer pelo Tratado de Ayacucho, de $1867^{22}$. A partir desse tratado, as ligações comerciais de fronteira possibilitaram normatizar o escoamento da produção boliviana, bem como a fácil entrada de trabalhadores bolivianos na província do Amazonas em uma livre mobilidade entre os dois países.

Neste sentido, algumas interpretações emergem, quando se percebe que os acordos firmados entre Brasil e a Bolívia, na questão da abertura à navegabilidade do Alto Madeira, se tornou uma política em que possibilitou uma espécie de migração de fuga de índios dos aldeamentos de Moxos e Chiquitos em direção à fronteira com Brasil. No território brasileiro se apresentavam como nacionais bolivianos. Essa dupla identidade (nacional boliviana e a indígena), promoveu as migrações e modalidades de fluxos complexas, bem como as diferentes interações nestas fronteiras amazônicas.

Esse acordo diplomático entre Brasil e Bolívia, tentava resolver também, os impasses referentes aos fluxos de trabalhadores brasileiros indo em direção as terras bolivianas, em um movimento desencadeado pelo boom da borracha, que promoveu conflitos entre brasileiros e bolivianos por reservas de seringais nessas terras de fronteira e em disputas.

O rio Madeira, além de se converter no centro de interesse estratégico tanto da Bolívia como do Brasil. Os seringueiros brasileiros começaram

\footnotetext{
${ }^{20}$ GARRETT, Ana Maria Lema. Frontera Permeable y Brazos Apetecidos: La migración de los indígenas Chiquitanos a Brasil em la Segunda mitad del siglo XIX. In: SILVA, Giovane José da. Entre Fronteiras Brasil-Bolívia: Relações Internacionais, Diplomacia e Política. São Paulo: Paco editorial, 2018.

${ }^{21}$ SENA, Ernesto Cerveira de. "El defensor de la frontera": a trajetória de Sebastián Ramos e as disputas fronteiriças (Brasil-Bolívia, 1825-1862). Tempo. Niterói: Scielo Analytics, 2020, vol. 26, n. 1, p. 113.

22 SENA, Ernesto Cerveira de. Acordo de Ayacucho - Territórios e as descontinuidades dos Tratados: Forjando Fronteiras, Elaborando Nações (Bolívia e Brasil: Época Colonial - 1967). Goiânia: IX Encontro Internacional da ANPHLAC (Associação de Pesquisadores e Professores de História das Américas), 26 de julho a 29 julho de 2010, 2010, ISBN 978-85-61621-03-2, p. 22.
} 
a exercer uma forte pressão avançando continuamente sobre o território boliviano subindo os cursos do Madeira, do Purus e do Yuruá. ${ }^{23}$

O acordo de Ayacucho também conhecido como o Tratado de Amizade, Limites, Navegação, Comércio e Extradição, delimitaria geograficamente uma vasta região entre Brasil e Bolívia, o que esperava-se resolver as questões diplomáticas de limites das suas fronteiras.

O Brasil compromete-se desde já a conceder á Bolívia [...], o uso de qualquer estrada, que venha a abrir, desde a primeira cachoeira, na margem direita do rio Mamoré, até a de Santo Antonio, no rio Madeira, a fim de que possam os cidadãos da Republica aproveitar para o transporte de pessoas e mercadorias, os meios que oferecer a navegação brasileira, abaixo da referida cachoeira de Santo Antonio. ${ }^{24}$

O acordo selado entre os dois países, "provocou objeção por parte do governo do Peru argumentando que os limites entre Bolívia e Peru nessa zona não estavam ainda definidos e, portanto, este trabalho era ofensivo para seus interesses." ${ }^{25}$ Conforme Luiz Alberto Moniz Bandeira, o Peru reclamava igualmente os territórios que a Bolívia cedera ao Brasil, com o Tratado de 1867 e começara no início do século XX, a apoderar-se manu militari da região no Alto Juruá. Essas intrusões de peruanos não ficaram restringidas apenas no Alto Juruá, expandindo-se para os territórios do Alto Purus, (e pelas evidências das fontes históricas, houveram invasões de caucheiros peruanos no território do Alto Madeira). Segundo ainda esse autor, as invasões peruanas e a tomada da posse eram praticadas através da violência, o que favoreceu a apropriação dos recursos naturais disponíveis nessa região arbitrariamente como à instalação de alguns pontos de apoio do comércio e extração de caucho nesses territórios. ${ }^{26}$

A instalação de pontos de comércio motivados pela extração do látex da seringueira e do caucho, esta última sendo uma forma de expansão da modalidade extrativa da Castilloa elastica, se estendia por macrorregiões amazônicas, pois o caucho era uma forma de extração predatória exercida por grupos sociais de uma categoria específica.

\footnotetext{
${ }^{23}$ CÓRDOBA, LORENA, 2012, p. 129, (tradução nossa).

24 DECRETO $\mathrm{n}^{\circ} 4.280$, de 28 de novembro de 1868 . Disponível em: http://www2.camara.leg.br/legin/fed/decret/1824-1899/decreto-4280-28-novembro-1868-553624-normape.html.

${ }^{25}$ BRIDIKNINA, Evgenia, 2018, p. 29, (tradução nossa).

${ }^{26}$ BANDEIRA, Luiz Alberto Moniz. O Barão de Rothschild e a Questão do Acre. Rev. Bras. Polít. 43 (2): 150-189, 2000.
} 


\section{As incursões más intencionadas no rio Madeira e em seus afluentes}

De acordo com Artur Cesar Ferreira Reis, quando Euclides da Cunha chegou "à Amazônia em 1905 junto a expedição da Comissão Brasileira de Limites com o Peru, em um momento de certa tensão, consequente a conflitos de expansão sobre as terras do Sul, onde bolivianos e peruanos possuíam também trechos daquela Amazônia que nós disputávamos". 27

O caucheiro é forçadamente um nômade votado ao combate, à destruição e a uma vida errante ou tumultuária, porque a castilloa elastica que lhe fornece a borracha apetecida não permite, como as heveas brasileiras, uma exploração estável, pelo renovar periodicamente o suco vital que lhes retiram. É excepcionalmente sensível. Desde que a golpeiem, morre, ou uma vez para aproveitá-la toda. Atora-a, depois, de metro em metro, desde as sapopembas aos últimos galhos das frondes; e abrindo no chão, ao longo do madeiro derrubado, rasas cavidades retangulares correspondentes às secções dos toros, delas retira, ao fim de uma semana, as planchas valiosas, enquanto os restos aderidos à casca, nos rebordos dos cortes, ou esparcos a esmo pelo solo, constituem, reunidos, o "sernambi" de qualidade inferior $[\mathrm{sic}] .{ }^{28}$

A exploração tanto das seringueiras quanto da extração do caucho produziria a cobiça de diferentes grupos sociais em explorarem os recursos naturais, em territórios indígenas. Assim, os grupos de caucheiros estavam em processo de esgotamento desse recurso natural em território peruano, por conta da derrubada das árvores do caucho. Atrás desse recurso, as entradas de caucheiros peruanos no território do Alto Madeira, promoveriam uma série de episódios fantasmagóricos e de conflitos, de pioneiros entre si, e de pioneiros contra os povos indígenas do Madeira.

A forma predatória utilizada na derrubada da árvore do caucho fez com que as reservas desse recurso natural rapidamente se esgotassem no território peruano, o que culminou com as incursões à procura de novas reservas naturais em territórios indígenas no Madeira. Nesse contexto da segunda década do século XX, tanto a borracha extraída da seringueira, como à extraída com a derrubada da Castilloa eslatica, vinham perdendo valor comercial, por conta do contrabando das sementes de seringueiras brasileiras pelos ingleses. As "sementes da Hévea brasiliensis levadas cladestinamente para o Oriente em 1873 pelo botânico James Collins, e em 1876 por Wickham, estava dando ótimo resultado científico e a borracha oriental ia se insinuando no mercado internacional

\footnotetext{
${ }^{27}$ CUNHA, Euclides da. Euclides e o Paraíso Perdido, Arthur Cesar Ferreira Reis. In: Um Paraíso Perdido: reunião de ensaios amazônicos. Brasília: Senado Federal, Conselho editorial, 2000, p. 47

${ }^{28}$ CUNHA, Euclides da. Um Paraíso Perdido: reunião de ensaios amazônicos, p. 161.
} 
sorrateiramente." 29 Consequentemente décadas mais tarde com a produção e exportação em larga escala da borracha produzida na Malásia e Índia, fez com que despencasse a exportação e os preços da borracha brasileira no mercado exterior.

Uma dessas incursões de coleta de sementes da hévea brasilienses, segundo Warren Dean, ocorreu no rio Madeira, e contou com o apoio de "um boliviano chamado Ricardo Chávez, que estivera envolvido no comércio de borracha como "patrão", isto é, um intermediário [...]. Chávez descera o rio Madeira com duzentos índios da tribo moxo e se estabelecera num lugar chamado Carapanatuba". ${ }^{30}$ Este teria uma demanda de fornecer "200 quilos de sementes", e que logo seriam "embaladas em seis barris, e estavam a caminho" da Inglaterra, onde "seriam despachados os barris para a Índia". ${ }^{31}$

Segundo Reinaldo Arruda, com a crise da economia gomífera nos anos de 1912 e 1913, "os seringais espalhados ao longo nos rios sedimentaram-se como unidades de dominação sobre aldeias". ${ }^{32}$ Isso favoreceu as ações estratégicas dos agentes intrusos em dominar territórios dos povos nativos, por meio das táticas de expulsão dos indígenas de suas terras, as chamadas "correrias", que poderiam ser tanto conflitos entre grupos de invasores entre si, ou sob ataque as aldeias indígenas, que promoveram raptos de crianças, o etnocídio cultural, o genocídio nas fronteiras ${ }^{33}$ e a arregimentação de diversos grupos étnicos nos territórios indígenas, bem como os casos em que constam da intrusão de caucheiros em territórios pertencentes aos índios Kawahíwa-Parintintin, no rio Madeira. ${ }^{34}$

A partir de uma leitura crítica do relatório, A Pacificação dos índios Parintintins: karó de iuirapá, escrito por Joaquim Gondim de Albuquerque Lins, publicado em 1925, e que a partir do seu acesso aos relatórios produzidos entre 1921 a 1923, por auxiliares que compuseram a equipe de Inspetoria do Serviço de Proteção aos índios no Rio Maicy-

\footnotetext{
${ }^{29}$ HUGO, Vitor. Desbravadores. São Paulo: Escolas profissionais salesianas, vol. 1, 1959, p. 222.

${ }^{30}$ DEAN, Warren. A luta pela borracha no Brasil: um estudo de história ecológica. Tradução: Eduardo Brandão. São Paulo: Nobel, 1989, p. 40.

${ }^{31}$ DEAN, Warren. Promoteu às avessas, 1855-1876. In: A luta pela borracha no Brasil: um estudo de história ecológica, 1889, p. 40.

32 ARRUDA, Rinaldo S. V. Fronteiras e Identidades: os povos indígenas na tríplice fronteira BrasilBolívia-Perú. Projeto História, São Paulo, n. 39, jul/dez. 2009, p. 165. pp. 159-179

${ }^{33}$ De acordo com os conceitos de etnocídio e genocídio definidos por Pierre Clastres, de que, "o etnocídio, portanto, é a destruição sistemática dos modos de vida e pensamento de povos diferentes daqueles que empreenderam essa destruição, [...], o genocídio assassina os povos em seu corpo”. CLASTRES, Pierre. do etnocídio. in: arqueologia da violência. São Paulo: brasiliense, 1982, p. 56.

${ }^{34}$ CAMPOS, Jorge de Oliveira. Migração, Guerra e a Etnogênese Kawahíwa-Parintintin: na História na Literatura. In: V SEMINÁRIO DE PÓS-GRADUAÇÃO EM HISTÓRIA - PPGH/UFAM, ST 02 História Indígena e do Indigenismo, sessão 02, FES - Faculdade de Estudos Sociais. Resumo. Manaus: PPGH/UFAM, 2019.
} 
Mirim, afluente do rio Madeira, bem como do seu acesso aos escritos de Nimuendajú de 1924, este que participou do processo de "pacificação" dessa etnia. Segundo esse relatório de Gondim,

[...], no período que decorreu de 1900 a 1915, eles [os Parintintin] tiveram de repelir, aliás com grandes perdas, dada a desigualdade de armas, repetidos ataques de expedições armadas e de numerosos caucheiros incendiários, que operaram de chofre, sobre as suas malocas, algumas situadas nos rios Maicy e Maicy-Mirim, outras no rio Ipixuna e outras ainda nos centros de vários seringais do Madeira. ${ }^{35}$

A penetração de caucheiros peruanos incendiários nos afluentes do rio Madeira, revela uma forma de contato bastante agressiva, os ataques das expedições armadas, praticados de forma a expulsar os grupos de índios Parintintin de suas terras, pois além da finalidade da exploração dos recursos naturais praticada pelos "caucheiros incendiários", que supostamente teriam também prestado serviços, como os de mercenários, aos poderosos seringalistas do Madeira, a fim de juntos afugentarem os índios, ocupando os territórios onde situavam seus ranchinhos e aldeias próximas as vias de acesso em áreas de seringais.

Segundo ainda Joaquim Gondim, dentre as decorrentes expedições feitas nesse rio pelos caucheiros incendiários, uma delas foi a chefiada pelo peruano Benjamim Maya, com número formidável de homens, teria objetivado o massacre dos indígenas Parintintin. ${ }^{36} \mathrm{O}$ referido relatório que fora publicado pela Comissão Rodon, detalha literalmente o cenário e a sanha do encontro dos "caucheiros sanguinários" com estes índios do tronco Tupi no rio Maicy, afluente do rio Madeira.

A cena ocorrerá no Maicy. Nesse tempo, fugindo da sanha dos caucheiros sanguinários, os Parintintin haviam se localizado num plano saliente, que domina dois estirões do estreito rio, hoje vulgarmente conhecido por barreira vermelha, armando os seus tapirys sobre a margem e transformando o lugar num cenários mais pitorescos, onde a atividade do selvícola se expandia na cultura da lavoura, vendo no trabalho rude e honesto o elemento capaz de atenuar as necessidades de sua vida meditativa e solitária. ${ }^{37}$

Segundo Gondim, o ataque praticado pela grande horda de caucheiros, chefiada pelo aventureiro Benjamim Maya, teve início na altura da "barreira vermelha". Afoito,

\footnotetext{
${ }^{35}$ GONDIM, Joaquim. A Pacificação do Parintintins: Karó dé iurapá. Commissão Rondon, n 87. 1925, p. 6.

${ }^{36}$ GONDIM, Joaquim. A Pacificação do Parintintins: Karó dé iurapá, p. 6.

${ }^{37}$ GONDIM, Joaquim. A Pacificação do Parintintins: Karó dé iurapá, p. 7, (grifo do autor).
} 
Maya teria dado a ordem à sua tropa para dispararem a primeira descarga de chofre, nos "ranchinhos"38 que repousavam sobre o limpo do barranco. ${ }^{39}$

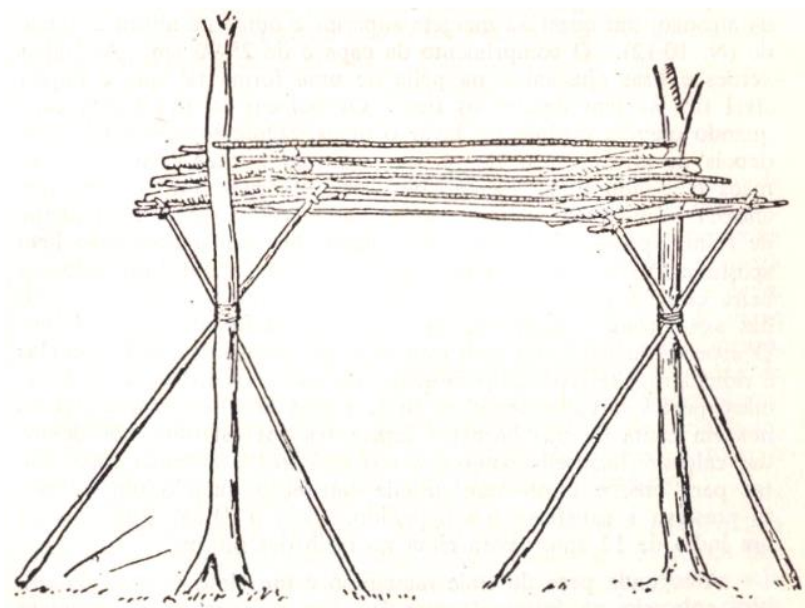

Imagem 2. Armação de rancho provisório em duas árvores, NIMUENDAJÚ, 1982, p. 101.

$\mathrm{O}$ ataque aos ranchinhos acabou culminando com os assassinatos de inúmeras famílias indígenas, silenciando-as. A matança dos Parintintin-Kahawíwa relatado por Gondim, demonstrou os objetivos dos grupos invasores, que foram o de destituir os índios de suas habitações, das suas terras cultivadas e de caças, pois acredita-se que mesmo com esse massacre alguns desses nativos foram deixados vivos, como o caso de mulheres e crianças indígenas sobreviventes das balas e que foram levadas forçadamente dos seus espaços socioculturais e familiares.

Segundo ainda Joaquim Gondim, alguns poucos índios Parintintin indomáveis nas suas últimas opções no conflito:

[...], atiravam-se do alto da barreira sobre o rio, de arco em riste, objetivando o batelão sinistro e desolador, de cujas bordas os expedicionários deflagraram os seus rifles, certeiramente, produzindo o aniquilamento e a morte. [...], os expedicionários completaram a objetiva empreitada, devastando as plantações e queimando os ranchinhos que encontraram sobre a sinistra barreira como corolário de uma obra que ainda revive entre as maldições da história." ${ }^{40}$

De forma, percebe-se que os contatos e interações conflitivas, foram sendo tecidos por um efeito da expansão das fronteiras transnacionais e por interesses do livre mercado,

\footnotetext{
${ }^{38}$ De acordo com Nimuendajú, dentre os diferentes ranchinhos produzidos pelos índios Parintintin do Rio Madeira, haviam as construções dos ranchos de caçadas, feitos com esteios de árvores vivas. Segundo ele, "todas as suas habitações, mesmo as provisórias, têm bastante altura para um homem ficar em pé dentro delas, [...], os cestos e mais utensílios estão pendurados em pequenas travessas de pau que pendem da armação da casa”. NIMUENDAJÚ, Curt. Textos indigenistas: relatórios, monografias, cartas. São Paulo: Ed. Loyola, 1982, p. 101, 102.

${ }^{39}$ GONDIM, Joaquim. A Pacificação do Parintintins: Karó dé iurapá, p. 7.

${ }^{40}$ GONDIM, Joaquim. A Pacificação do Parintintins: Karó dé iurapá, p. 8.
} 
violando as fronteiras étnicas, cometendo o etnocídio cultual, praticados por forças hegemônicas operacionalizadas em territórios indígenas.

Segundo a publicação no jornal, Extremo Norte, de 1913, esse território era considerado uma "zona rica em seringais" onde as continuas disputas no Vale do Madeira envolvendo proprietários de terras em desavenças e perseguições aos nativos indígenas eram recorrentes. Sabe-se que através desse jornal, as tais práticas e ações da elite local contrariavam normas de proteção ao índio, "previstas no Serviço de Catechese", acarretando penalidades aos transgressores. ${ }^{41}$

De acordo ainda com o jornal Extremo Norte, de 1913, que deixa transparecer à inviabilização das denúncias e ações punitivas aos proprietários de terra, o que possibilitou abrir margens para outras ações de intrusão praticadas por empresas extrativista e por caucheiros peruanos. Estes invasores agiam penetrando no território do Alto Madeira, por rios e afluentes, nos quais promoveriam contínuos processos de exploração dos recursos naturais de forma predatória. ${ }^{42}$

Segundo José Carlos Meireles, a formação desses grupos invasores que adentravam pelas fronteiras limítrofes brasileira, estava ligada diretamente a um recrutamento de grupos étnicos contactados pela frente pioneira, como: os índios Ashaninka e Kaxinawá, falantes das línguas panos e aruak, grupos que ocupavam as cabeceiras dos rios Acre, Iaco, Chandles, Purus, Envira, Juruá, e que integravam a "expansão da frente exploratória". 43

Portanto, na tentativa de encontrar respostas em explicar as origens desses grupos étnicos que compuseram a frente de expansão boliviana e peruana no Alto Madeira, se torna complexa, a partir do ponto em que se tenta evidenciar as etnias ou grupos étnicos que integravam as expedições. Assim, revelou-se que os grupo arregimentados, faziam parte de uma espécie de magma de grupos panos-falantes que rasga transversalmente territórios bolivianos, fronteiras peruanas e seus limites com o Brasil. ${ }^{44}$ Dessa forma, percebe-se que, as fronteiras étnicas e limites de encontros necessitaram ser analisadas em conjunto com a compreensão tradicional das fronteiras demarcatórias estabelecidas pelos Estados Nacionais, e não de forma díspares, de modo que se entenda que os acordos

\footnotetext{
${ }^{41}$ PERIÓDICO, Extremo Norte. Santo Antonio Do Madeira, 1 de Novembro, no 20, 1913, p. 2.

42 PERIÓDICO, Extremo Norte, 1913, p. 2.

${ }^{43}$ MEIRELES, José Carlos. Os Índios Isolados no Acre seus Territórios. In: Povos indígenas no Brasil: 2006/2010, p. 519.

${ }^{44}$ CÓRDOBA, Lorena; VILLAR, Diego. As estruturas de nominação étnicas na história dos panos meridionais. In:_Orgs. LIMA, Edilene Caffaci de; CÓRDOBA, Lorena. Os Outros dos Outros: Relações de alteridade na Etnologia Sul-Americana. Curitiba: Ed. UFPR, 2011, p. 117
} 
diplomáticos como, o "Tratado de Petrópolis, de 1903" "45, não resolveu de imediato as relações intricadas nas fronteiras do Alto Madeira, mas o acordo diplomático que de certa forma resolveu no papel as questões demarcatórias, na qual viabilizou-se a anexação do Acre ao Brasil. Além disso, houve na assinatura a promessa da construção de uma ferrovia que ligaria à Bolívia ao Brasil, assim como o pagamento de 2 milhões de libras esterlinas, "pagos à Bolívia a título de indenização, que seriam utilizados na construção de estradas e outras melhorias que a exemplo da estrada Madeira-Mamoré, também contribuíram para incrementar as relações comerciais entre os dois países". ${ }^{46}$

Portanto, o acordo foi vantajoso para ambos países pois tinham interesses em comum, embora o tratado não resolveu os conflitos acarretados pelas diferentes intrusões de grupos maus intencionados em território indígenas fronteiriços. Por outro lado, a vinda de trabalhadores para o território do Alto Madeira, que eram deslocados para os trabalhos na construção da Estrada de Ferro Madeira-Mamoré, nas obras geograficamente situadas entre o distrito de Santo Antônio no território brasileiro à Guajará-Mirim na fronteira desse país com à Bolívia, trabalhadores que estavam sendo inserindo nessas diferentes territorialidade a partir de fluxos contínuos.

\section{A frente de Trabalhadores na Madeira-Mamoré}

Com à construção da Estrada de Ferro Madeira-Mamoré, um projeto de modernização para a região que acarretou na vinda de diferentes levas de trabalhadores para o território do Alto Madeira, estas massas de trabalhadores que iam sendo recolocados aos postos de trabalho desde a primeira fase da construção, por volta de 1867 , sendo eles inseridos na frente de trabalho da ferrovia, na colocação dos trilhos, e nas funções específicas de trabalho na ferrovia, nas quais incluiriam engenheiros, topógrafos, desenhistas, funcionários de escritórios e médicos, dentre outros ${ }^{47}$.

De acordo com a literatura histórica de Rose Neeleman, onde a autora em seu livro, trilhos na selva, retrata diversos fatos documentados acerca do dia a dia dos trabalhadores da Ferrovia Madeira - Mamoré, nos últimos anos da construção, por volta

\footnotetext{
45 RIO BRANCO, Barão do; BRASIL, Assis. O Tratado de Petrópolis, assinado em 17 de novembro de 1903 pelo BARÃO DO RIO BRANCO e ASSIS BRASIL, foi aprovado por lei federal de 25 de fevereiro de 1904, regulamentada por decreto presidencial de 7 de abril de 1904, incorporando o Acre como território brasileiro. Disponível em: http://www.newmarc.com.br/drws/tratado.pdf.

46 ANDRADE, José H. Fischel de; LIMOEIRO, Danilo. Rui Barbosa e a política externa brasileira: considerações sobre a Questão Acreana e o Tratado de Petrópolis (1903). Rev. Bras. Polít. Int. [online], 2003, v. 46 n.1, p. 97-117.

${ }^{47}$ FERREIRA, Manoel Rodrigues. A ferrovia do diabo, p. 148, 174.
} 
de 1908 a 1913. Em um anúncio publicado no Engineering News, jornal voltado à engenharia, anunciava empregos para engenheiros ferroviários com experiência de pelo menos um ano em projetos nos trópicos. O salário variava de 125 dólares a 250 dólares por mês em ouro americano, enquanto em Nova York se recebiam por mês em média 75 dólares. Esses anúncios contagiavam milhares de homens em direção à floresta sulamericana. Os trabalhadores eram levados para a Amazônia em pequenos barcos a vapor, primeiramente até Manaus e dali até Porto Velho. A maioria dos trabalhadores se alocavam em acampamentos próximos aos trilhos, em um percurso que se firmaria até Guajará-Mirim $^{48}$.

Os grupos sociais alocados nessas regiões fronteiriças vivenciaram experiências em um ambiente engendrado por desilusões, e por "um efeito fantasmagórico" dos homens a uma paisagem de fronteira hostil em plena selva amazônica. Esses trabalhadores que continuamente eram substituídos dos seus postos de trabalho, "levas e mais levas de homens contratados em todas as partes do mundo vinham substituir os que, tendo chegado um, ou dois, ou três meses antes, já se encontravam mortos ou completamente inutilizados. ${ }^{49}$ E dessa maneira, a construção da ferrovia progredia.

Esse mecanismo que regulava os trabalhos em território de fronteira, foi imposto por concessionárias, que desde a primeira empreitada da construção da Estrada de Ferro Madeira Mamoré, iniciada por George Earl Church, por volta de 1867 e que abandonou a concessão por falta de investimento em 1879, com apenas 7,5 quilômetros de trilhos construídos. O retorno e conclusão desta obra na selva só foi concluída em 1912 pelo grupo Farquhar, que viria a assentar o "cravo de ouro" em Guajará-Mirim ${ }^{50}$. Esses espectros do capitalismo corroboraram para as transformações das paisagens de fronteira e a inserção das massas de trabalhadores em um canteiro de obras nos confins da Amazônia.

Uma experiência vivida por um trabalhador da ferrovia situada nas fronteiras do Alto Madeira, foi bem descrita em um poema, "A terra das Seringueiras", escrito por R. S. Stout, e encontrado na Coleção do fotógrafo oficial da E. F. M. M., Dana Merril, disponibilizado no livro Trilhos na Selva. Alguns fragmentos desse poema ajudam a traçar o quadro da realidade vivida pelos trabalhadores alocados nessa região.

\footnotetext{
48 NEELEMAN, Rose; NEELEMAN, Gary. Trilhos na selva: o dia a dia dos trabalhadores da Ferrovia Madeira-Mamoré. São Paulo: BEI comunicação, tradução: Ibraíma Dafonte Tavares, 2011, p. $98,99$.

${ }^{49}$ FERREIRA, Manoel R. A ferrovia do diabo, p. 272.

${ }^{50}$ NEELEMAN, Rose; NEELEMAN, Gary. Trilhos na selva, p. 85 - 99.
} 
É uma velha zona quente, a "Zona ardente",

Esta terra de árvores de borracha,

De febre e calafrios e seus sacrifícios,

Entre rios correndo para as terras baixas.

É uma velha zona quente como o inferno,

E não fica nada longe dos desvãos

Onde o diabo cozinha seus fantasmas

E dança e salta em torno de seus caixões [...]

[...] A selva é tudo que se pode querer,

Com seus insetos que não picam, mas mordem,

Cobras, lagartos e jacarés aos bandos,

Que oferecem brigas de primeira ordem.

[...] Será que lamentamos estar aqui,

Nesta terra de árvores de borracha?

Chove todo dia, mas ainda bem,

Pois o que se quer é voltar para casa. ${ }^{51}$

O poema escrito por R. S. Stout, mostra o pensamento que ilustra o cotidiano dos trabalhadores subalternizados inseridos nesses espaços e limites de fronteiras, na qual a "modernidade" promoveria não apenas as lamentações provocadas pelas doenças, desgastes físicos e psicológicos dos trabalhadores, mas como afirma o Sanitarista Oswaldo Cruz, que em 1910 esteve em Porto Velho e "declarara que a malária ${ }^{52}$ matava uma vida por dia, e inutilizava talvez dez". 53

Esses trágicos relatos evidenciam um pouco o mundo do trabalho na Amazônia, que se configurou no contexto histórico do Alto Madeira no início do séc. XX, o que deixou marcado memórias sociais que trouxeram à tona uma mudança brusca de vida ou um cataclismo evidenciado pelos grupos sociais que se dirigiam a essa região insalubre.

Recuando para meados do século XIX, na qual a abordagem sobre as primeiras ocupações advindas das entradas sertanistas e da formação de núcleos populacionais em torno da região do Alto Madeira, nos dizem que "essas gentes viviam espalhadas, em quase dispersão, ao logo da margem dos grandes rios. Os agrupamentos dos povoados e vilas eram de pouca monta. No Madeira, estendiam-se até Santo Antônio, onde se raia a Província com o Mato Grosso ${ }^{54 \%}$.

Os dados dos contingentes populacionais deslocados para a região do Alto Madeira seria uma parcela de "gentes de Cametá, Santarém, Óbidos e outros lugares do

\footnotetext{
${ }^{51}$ MERRIL, Danna. The Land of Rubber-Gun Tree. Collections, New York. (1909). In: NEELEMAN, Rose; NEELEMAN, Gary. Trilhos na Selva, 2014, p. 92 - 93.

52 A malária é uma doença infecciosa febril aguda, causada por protozoários, transmitido pela fêmea infectada do mosquito Anafheles. A maioria dos casos de malária se concentra na região Amazônica (Acre, Amazonas, Mato Grosso, Pará, Rondônia, Roraima e Tocantins), área endêmica para a doença. Disponível em: portalsaude.saude.gov.br. Acesso em: 28 de Dezembro de 2019.

${ }^{53}$ FERREIRA, Manoel Rodrigues, p. 271.

${ }^{54}$ REIS, Arthur César. Província do Amazonas. In: REIS, Arthur César. História do Amazonas. Belo Horizonte: Itatiaia, 1989. p. 217.
} 
Pará. Vieram espontaneamente e em tal quantidade que, somados quantos lá encontrava, acendiam, só no Alto Madeira, em 1858 a cinco mil pessoas ${ }^{55 \%}$. A estatística trazida por Arthur Cesar Ferreira Reis, sobre a ocupação nessas paragens, soma-se com as ideias incutidas no imaginário coletivo dos sujeitos históricos que migravam pelas rotas e por conexões interprovinciais em direção as essas territorialidades, incutiam na cabeça desses trabalhadores promessas de enriquecimento fácil, quase sempre eram apenas ludibriados pelos agenciadores da Companhia de Navegação do Amazonas nos portos e entrepostos das Províncias e convencidos a embarcarem para o extremo Norte.

Esse método de agenciamento, aponta o professor Francisco Foot Hardman, teve “à semelhança do tráfico de escravos, envolveu agentes dedicados exclusivamente ao recrutamento, transporte e reposição contínua de estoques de trabalhadores para as companhias construtoras. Daí o trabalho compulsório, estamos a um passo" 56 .

Nos anos que sucederam a década de 1870, houve empreitadas para a realização das primeiras tentativas de construir uma estrada que ligasse os trechos encachoeirados do Alto rio Madeira. Foi constatado que dentre as expedições a cruzarem o vasto território amazônico em direção para o Alto Madeira, estiveram nesse processo as levas de trabalhadores para a construção da Estrada de Ferro Madeira Mamoré. Segundo as informações prestadas pelo engenheiro Feliciano Antonio Benjamim, que compunha o quadro de trabalhadores técnicos a serviço do Sr. Thomas Collins,

[...], o pessoal empregado na estrada de 800 homens, sendo 500 americanos e italianos (estes em pequeno número) e 300 bolivianos, tendo o empresário Thomaz Collins contractado ultimamente com o cidadão José Paulino won Hoonholtz a introdução de 600 brasileiros, que este cidadão foi buscar no Ceará. ${ }^{57}$

Os trabalhadores vindos dos Estados Unidos “(...) desembarcaram em Santo Antônio procedentes da Filadélfia, 719 pessoas, inclusive seis mulheres”. Além dos trabalhadores da fronteira Brasil e Bolívia e do litoral nordestino, que "foram recrutados através de agentes locais, cerca de 200 índios bolivianos e quinhentos cearenses". Também nas notas explicativas da obra de Foot Hardman, afirma que “(...), quanto aos

\footnotetext{
${ }^{55}$ REIS, Arthur César. História do Amazonas, p. 217.

${ }^{56}$ FOOT HARDMAN. Trem Fantasma, p. 127.

57 RELATÓRIO. Fala com que abriu no dia 25 de agosto de 1878 a 1.a sessão da 14.a legislatura da Assembleia Legislativa Provincial do Amazonas o exim. O Senhor Barão de Maracajú, presidente da província. Manáos, Typ. do Amazonas, 1878, (89 AN), p. 57
} 
cearenses, Craig fala em quatrocentos cearenses, e M.R. Ferreira, sempre muito preciso, em quinhentos." 58

Essas categorias sociais de migrantes nacionais que eram arregimentadas para os trabalhos subalternizados exercidos no front da construção da ferrovia Madeira-Mamoré, eram considerados para a companhia concessionária $P . \&$ T. Collins, da Philadelphia, mão-de-obra substituível. Os trabalhadores eram fisicamente degenerados e hepáticos, pois eram submetidos a trabalhos penosos, atacados por moléstias que logo os acometiam em sequência eram substituídos. Seguindo a lógica capitalista de uma espécie de trabalhador provisório a serviço da concessionária, pois um corpo desgastado de uma longa viagem e a insalubridade do ambiente de trabalho, adoeciam e logo eram inutilizados.

Segundo o relatório da Província do Amazonas, percebe-se que as condições de trabalho impostas pela empresa $P . \& T$. Collins, aos trabalhadores subalternizados se tornava um motivo de insatisfação, o que acarretou uma "revolta contra o empresário da estrada de ferro Madeira-Mamoré”. Sendo esta revolta contida por uma guarnição policial enviada pelo presidente da província do Amazonas, no qual culminou com "a prisão de nove indivíduos cabeças de tal sublevação". 59

Esses trabalhadores eram transportados por navios a vapores em linhas administradas por particulares nacionais e pelas companhias estrangeiras, que transportavam essas gentes dos seus locais de origem para os limites do Alto Madeira. Logo se percebe que para compor essa mão de obra, era necessário mais contingentes de trabalhadores, pois o Decreto de 1866, que abriu a navegação no rio Amazonas a todas as bandeiras, abrangeu para as rotas de navegação para o rio Madeira, no qual foram sendo ampliadas os navios de bandeiras estrangeiras ${ }^{60}$. No decorrer da abertura da navegabilidade do rio Amazonas e seus tributários, os navios de bandeiras estrangeiras passaram fazer o mesmo percurso dos navios de bandeira nacional, o que gerou um maior fluxo no rio Madeira.

Neste sentido, a abertura da navegabilidade promoveu uma dinâmica de deslocamentos populacionais, em um mecanismo que moviam as massas a adentrar os

\footnotetext{
58 HARDMAN, Foot. Trem fantasma, 1988, p. 130, 238.

${ }^{59}$ SECRETARIA DE POLÍCIA DA PROVÍNCIA DO AMAZONAS. Relatório e Anexo. 25 de agosto de 1878, fala com que abriu no dia a 1, a sessão da 14, a legislatura da Assembleia Legislativa Provincial do Amazonas o exim. O Senhor Barão de Maracajú, presidente da província. Manáos, Typ. do Amazonas, 1878.

${ }^{60}$ PALM, Paulo Roberto. A abertura do rio Amazonas à navegação internacional e o parlamento brasileiro, 2009.
} 
novos espaços fronteiriços. As consequências disto, além do trabalho compulsório análogo a um regime de escravidão, foram as contendas e conflitos com os povos indígenas que já ocupavam àquela região. Assim como, a insalubridade do lugar, as doenças tropicais e outras mazelas, fizeram da ocupação definitiva e da exploração dos recursos naturais, um desafio para os que se arriscavam a adentrar os territórios hostis do Alto Madeira.

O percurso que compreende à construção da Estrada de Ferro Madeira-Mamoré, entre Guajará-Mirim e Santo Antônio, teve uma extensão de 400 quilômetros, na qual existia mais de vinte cachoeiras, algumas em proximidade e situadas em territórios indígenas que eram contrários ao avanço adventício. No início do século XX, no ano de 1909, a cidade de Porto Velho estava sendo erguida e abrigou uma população de aproximadamente mil pessoas, esta localidade, assim como, o vilarejo de Santo Antônio e São João do Crato, seriam localidades onde a incidência de conflitos entre os de fora contra os índios ganharia maior expressividade, tanto nos documentos oficias, quanto nos relatos de viajantes e jornais da época.

Assim como, nesse contexto, localidades como a Porto Velho foram sendo construídas em uma área de alguns alqueires em que "iniciaram as empresas norteamericanas a construção das instalações necessárias para moradia do pessoal categorizado" "61, da ferrovia Madeira - Mamoré. Essa frente de trabalhadores viria a ser composta nesse segundo momento, por diferentes povos de outras nacionalidades, como os trabalhadores provenientes de "Barbados, Trinidad, Cuba e outras ilhas do Caribe; os espanhóis da Galiza [...]"62 entre outros.

Desta forma, um evento que mexeu com a mobilidade no rio Madeira na primeira década do século XX, de acordo com o periódico, The Porto Velho Marconigram, que publicou uma matéria sobre um episódio de conflito entre trabalhadores alemães enviados a Madeira-Mamoré e índios. A narrativa construída pelo jornal demonstra a desilusão percebida por estes estrangeiros no trajeto que os levou a atravessar o vasto território, e ao perceberem que as espacialidades iam se tornando mais perigosas e amedrontadoras a cada trecho percorrido deixava-os aflitos. O desembarque destes trabalhadores alemães em Porto Velho, segundo o jornal, "recusaram-se a desembarcar e só o fizeram depois de cumpridas algumas exigências, em que se fez acompanhar da notícia de que nenhum

\footnotetext{
${ }^{61}$ FERREIRA, Manoel Rodrigues, 1960. p. 248.

62 NEELEMAN, Rose. Trilhos na selva: o dia a dia dos trabalhadores da Ferrovia Madeira-Mamoré; tradução: Ibraíma Dafonte Tavares. São Paulo: BEI comunicação, 2011. p. 131.
} 
alimento seria enviado ao barco.” Dessa forma, os impasses estavam levando o que seria uma eventual contratação de trabalhadores, passaram para discussões de um possível conflito armado por comida, entre alemães e os funcionários alocados em Porto Velho. Segundo ainda o jornal, a visão de "civis armados provocou efeito esperado, e nesse momento as autoridades assumiram uma postura conciliatória e aceitaram algumas exigências dos alemães, evitando que mergulhássemos em uma guerra civil na selva." ${ }^{3}$ Apesar do caráter conciliatório, poucos alemães decidiram ficar, conforme trata o Jornal, logo depois desse episódio,

[...] um grupo de nove homens tentou navegar em uma jangada improvisada. Nunca mais foram vistos; cinco deles tiveram a cabeça encontrada tempos depois, flutuando no rio. A chance de chegar à costa numa jangada era mesmo pequena na terra dos jacarés e dos mosquitos, mesmo que não fosse preciso atravessar o território dos hostis índios parintintins e dos cangas-pirangas (cabeças vermelhas), no rio Jamari. Quando o governo alemão soube do acorrido, pôs fim a esse tipo de imigração. Mais ou menos na mesma época, ao saber das doenças, das mortes e de outros problemas, vários outros países também proibiram a imigração de seus cidadãos para trabalhar na Madeira-Mamoré, entre os quais Portugal, Espanha, Itália e até mesmo Cuba. ${ }^{64}$

Os desentendimentos que ocorriam na localidade de Porto Velho acabaram produzindo receios à mobilidade no Madeira; a proibição dos governos estrangeiros em agenciar trabalhadores após o jornal evidenciar as atrocidades emplacadas pelos nativos, mencionando os grupos étnicos Parintintin e os Cangas-Pirangas como prováveis suspeitos de assassinar os cinco alemães desertores. Essas acusações se basearam na fama e da atuação guerreira desses indígenas, um padrão semelhante aos atos perpetrados por grupos nativos assentados nesta região de fronteira, os atos demonstram claramente que os índios eram contra o avanço adventício nessas paragens.

\section{Considerações finais}

Portanto, com as ocupações das terras indígenas pelas frentes expansionistas, que promoveram de certa forma a formação de agrupamentos, a fim de concluir o projeto da construção ferroviária em conjunto com as políticas de incentivo a exploração de recursos

\footnotetext{
${ }^{63}$ NEELEMAN, Rose. Trilhos na selva: o dia a dia dos trabalhadores da Ferrovia Madeira-Mamoré, p. 134.

${ }^{64}$ NEELEMAN, Rose. Trilhos na selva: o dia a dia dos trabalhadores da Ferrovia Madeira - Mamoré, p. 136, (grifo do autor).
} 
naturais e de escoamento da produção. Políticas essas, iniciadas ainda em meados do século XIX, conforme as tratativas firmadas em 1867, onde a constituição dos limites fronteiriços se estendera até o início do século XX, já no início do Brasil República. Por outro lado, as políticas de proteção aos povos indígenas proposta por um modelo rondoniano, foram ineficazes na prática.

Em meio a um contexto de conflitos e resistências, os acordos diplomáticos não chegaram a incluir cláusulas que favorecessem negociações com os povos nativos do Alto Madeira, invisibilizando-os, e criando com isso, demarcações sobrepostas às conhecidas e reivindicadas pelos índios, alavancando ainda mais os conflitos e resistências nativas nesse território litigioso.

Portanto, essas políticas demarcatórias estabelecidas pelos Estados Nacionais, promoveram ondas de intrusões em terra indígenas, provocando ainda mais os conflitos entre os povos indígenas do lado brasileiro e grupos invasores, como os evidenciados entre os anos de 1900 a 1915 em terras Parintintin. Por outro lado, a incorporação e subserviência de grupos étnicos às políticas identitárias nacionalistas promovidas pelos Estados Nacionais e postos em práticas com a arregimentação de grupos étnicos pelas frentes expansionistas, demonstraram que o domínio hegemônico não abarcou apenas a posse das terras e o controle das reservas naturais, chegou também ao domínio das classificações identitárias dos povos que adentravam o Alto Madeira. Nesta fronteira, as identidades nacionais também sobrepuseram as identidades étnicas, o que ficou evidentes quando se referem aos grupos indígenas incorporados nas frentes de expansão, classificando-os em, "peruanos" e "bolivianos", o que demonstra que as políticas nacionalistas dos Estados Nacionais Sul-americanos, Brasil, Peru e Bolívia, estavam para além das questões de expansão territorial e limites fronteiriços, avançando em um campo profundo e problematizador, o da constituição das identidades nacionais e das políticas de dominação aos povos indígenas. Mesmo às construções das identidades nacionais serem de cunho nacionalista, os grupos que avançaram sobre os territórios fronteiriços, souberam usar a partir de suas estratégias etnopolíticas, vantagens de passes e mobilidades nas fronteiras do Alto Madeira, amparados pelo Tratado de Ayacucho, de 1867, em que favoreceu o uso das suas identidades nacionais. Assim, esses grupos puderam escamotear suas identidades étnicas e assim não serem subjugados, capturados, bem como terem livre acesso aos territórios brasileiro, tornando suas negligências, assaltos e assassinatos em zonas litigiosas, impunes, sendo de responsabilidades das 
diplomacias republicanas em resolver estas questões de litígio décadas mais tarde por vias diplomáticas.

Data de submissão: $28 / 08 / 2020$

Data de aceite: 04/03/2021 


\section{Referências Bibliográficas}

ANDERSON, Benedict. Censo, mapa, museu. In: Comunidades imaginadas: reflexões sobre a origem e a difusão do nacionalismo. São Paulo: Companhia das Letras, tradução, Denise Bottman, 2008.

ANDRADE, José H. Fischel de; LIMOEIRO, Danilo. Rui Barbosa e a política externa brasileira: considerações sobre a Questão Acreana e o Tratado de Petrópolis (1903). Rev. bras. polit. int. [online]. 2003, vol.46, n.1, pp. 94-117.

ARRUDA, Rinaldo S. V. Fronteiras e Identidades: os povos indígenas na tríplice fronteira Brasil-Bolívia-Perú. Revista do Programa de Estudos Pós-Graduados de História. São Paulo: Projeto História, n. 39, jul/dez. 2009, pp. 159-179.

BANDEIRA, Luiz Alberto Moniz. O Barão de Rothschild e a questão do Acre. Rev. bras. polít. int. [online]. 2000, vol.43, n.2, pp. 150-169. Disponível em: https://www.scielo.br/scielo.php?pid=S0034-

73292000000200007\&script=sci_abstract\&tlng=pt

BARROS, José D’Assunção. História, Espaço, Geografia: diálogos interdisciplinares. Petrópolis, RJ: Vozes, 2017, 222p.

BASTOS, Aureliano Cândido Tavares. O vale do Amazonas: A livre navegação do Amazonas, estatística, producções, commercio, questões ficaes do Valle do Amazonas. São Paulo: Companhia Editora Nacional, 2. ed., 1937, p. 222, 223.

BRIDIKNINA, Evgenia. Conformación de espaço fronterizo Bolívia - Brasil em las primeras décadas del siglo XX. In: SILVA, Giovane José da. Entre Fronteiras BrasilBolívia: Relações Internacionais, Diplomacia e Política. São Paulo: Paco editorial, 2018.

CAMPOS, Jorge de Oliveira. Caminhos da Guerra: os índios Parintintin e as frentes de expansão seringalista no rio Madeira (1853 - 1923). Dissertação, (Mestrado em História), Instituto de Filosofia, Ciências Humanas e Sociais, Universidade Federal do Amazonas, 2019.

CAMPOS, Jorge de Oliveira. Migração, Guerra e a Etnogênese Kawahíwa-Parintintin: na História na Literatura. In: V SEMINÁRIO DE PÓS-GRADUAÇÃO EM HISTÓRIA - PPGH/UFAM, ST 02 - História Indígena e do Indigenismo, sessão 02, FES - Faculdade de Estudos Sociais. Resumo. Manaus: PPGH/UFAM, 2019.

CALDAS, Sérgio Túlio. Portos do Brasil = The Ports of Brazil. São Paulo: Horizonte, 2008.

CLASTRES, Pierre. Do etnocídio. in: arqueologia da violência. São Paulo: brasiliense, 1982.

CÓRDOBA, Lorena; VILLAR, Diego. As estruturas de nominação étnicas na história dos panos meridionais. In: Org. LIMA, Edilene Caffaci de; CÓRDOBA, Lorena. Os Outros dos Outros: Relações de alteridade na Etnologia Sul-Americana. Curitiba: Ed. UFPR, 2011. 
CUNHA, Euclides da. Euclides e o Paraíso Perdido, Arthur Cesar Ferreira Reis. In: Um Paraíso Perdido: reunião de ensaios amazônicos. Brasília: Senado Federal, Conselho editorial, 2000.

CUNHA, Euclides da. Um Paraíso Perdido: reunião de ensaios amazônicos. Brasília: Senado Federal, Conselho editorial, 2000. Ver em: https://www2.senado.leg.br/bdsf/bitstream/handle/id/1038/573595.pdf

CURT NIMUENDAJÚ. Os Índios Parintintin do Rio Madeira. In: Journal de la Société des Américanistes. Tome 16, 1924.

DEAN, Warren. A luta pela borracha no Brasil: um estudo de história ecológica. Tradução: Eduardo Brandão. São Paulo: Nobel, 1989.

DECRETO $\mathrm{N}^{\circ}$ 4.280, De 28 De Novembro De 1868, que Promulga o Tratado de Amizade, Limites, Navegação, Commereio e Extradição, Celebrado em 27 de março de 1867, entre o Brasil e a Republica de Bolívia. Disponível em: http://www2.camara.leg.br/legin/fed/decret/1824-1899/decreto-4280-28-novembro1868-553624-norma-pe.html

FERREIRA, Manoel Rodrigues. A ferrovia do diabo. São Paulo: Edições melhoramentos, 1960. 344p.

GARRETT, Ana Maria Lema. Frontera Permeable y Brazos Apetecidos: La migración de los indígenas Chiquitanos a Brasil em la Segunda mitad del siglo XIX. In: SILVA, Giovane José da. Entre Fronteiras Brasil-Bolívia: Relações Internacionais, Diplomacia e Política. São Paulo: Paco editorial, 2018.

GOES FILHO, Synesio Sampaio. As Fronteiras do Brasil. Brasília: FUNAG, 2013.

GONDIM, Joaquim. A Pacificação do Parintintins: Karó dé iurapá. Commissão Rondon, $\mathrm{n}^{\mathrm{o}}$ 87. 1925. Disponível em: http://www.etnolinguistica.org/biblio:gondim2001-parintintins

HUGO, Vitor. Os desbravadores. São Paulo: Escolas Profissionais Salesianas, 1959. $294 p$.

LUZ, Nicia Vilela. A política amazônica das repúblicas ribeirinhas e a diplomacia continental. In: A Amazônia para os negros americanos. Rio de Janeiro: Editora Saga, 1968, 188p.

MARTINS, José de Souza. Fronteira: a degradação do outro nos confins do humano. São Paulo: Contexto, 2. ed., 2018.

MEIRELES, José Carlos. Os Índios Isolados no Acre seus Territórios. In: Povos indígenas no Brasil: 2006/2010. 519p.

MELLO, Mauro Pereira de. A questão de limites entre os Estados do Acre, do Amazonas e de Rondônia (Aspectos Históricos e Formação de Território). Revista Brasileira de Geografia. Rio de Janeiro, Fundação Instituto Brasileiro de Geografia e Estatística, 1990, v. 52, n. 4 , pp. $7-71$. 
MERRIL, Danna. The Land of Rubber-Gun Tree. Collections, New York. (1909). In: NEELEMAN, Rose; NEELEMAN, Gary. Trilhos na Selva, 2011.

NEELEMAN, Rose; NEELEMAN, Gary. Trilhos na selva: o dia a dia dos trabalhadores da Ferrovia Madeira-Mamoré. São Paulo: BEI comunicação, tradução: Ibraíma Dafonte Tavares, 2011.

PALM, Paulo Roberto. A abertura do rio Amazonas à navegação internacional e o parlamento brasileiro. Brasília: Fundação Alexandre de Gusmão, 2009. 97p.

PERIÓDICO, Extremo Norte. Santo Antonio do Madeira, 1 de novembro, nº 20, 1913.

PONTES, Kassius Dinis da Silva. Euclides da Cunha, o Itamaraty e a Amazônia. Brasília: Funag, 2005, 150p.

POUTIGNAT, Philippe. Teorias da etnicidade. Seguido de Grupos étnicos e suas fronteiras de Fredrik Barth. São Paulo: Fundação Editora UNESP, Tradução: Elcio Fernandes, 1998, p. 229.

REIS, Arthur César. Província do Amazonas. In: REIS, Arthur César. História do Amazonas. Belo Horizonte: Itatiaia, 1989.

RELATÓRIO. Fala com que abriu no dia 25 de agosto de 1878 a 1.a sessão da 14.a legislatura da Assembleia Legislativa Provincial do Amazonas o exim. O Senhor Barão de Maracajú, presidente da província. Manáos, Typ. do Amazonas, (89 AN), 1878.

RIO BRANCO, Barão do; BRASIL, Assis. O Tratado de Petrópolis, assinado em 17 de novembro de 1903 pelo BARÃO DO RIO BRANCO e ASSIS BRASIL, foi aprovado por lei federal de 25 de fevereiro de 1904, regulamentada por decreto presidencial de 7 de abril de 1904, incorporando o Acre como território brasileiro. Disponível em: http://www.newmarc.com.br/drws/tratado.pdf.

SANTOS-GRANERO, Fernando; BARCLAY, Frederica. La frontera Domesticada: História econômica y social de Loreto, 1850 - 2000. Perú: Fondo editorial. 2002. 546 p.

SECRETARIA DE POLÍCIA DA PROVÍNCIA DO AMAZONAS. Relatório e Anexo. 25 de agosto de 1878, fala com que abriu no dia a 1, a sessão da 14, a legislatura da Assembleia Legislativa Provincial do Amazonas o exim. O Senhor Barão de Maracajú, presidente da província. Manáos, Typ. do Amazonas, 1878.

SENA, Ernesto Cerveira de. "El defensor de la frontera": a trajetória de Sebastián Ramos e as disputas fronteiriças (Brasil-Bolívia, 1825-1862). Tempo. Niterói: Scielo Analytics, 2020. Disponível em: https://www.scielo.br/scielo.php?script=sci_arttext\&pid=S1413$\underline{77042020000100092 \& t \operatorname{lng}=p t}$

SENA, Ernesto Cerveira de. Acordo de Ayacucho - Territórios e as descontinuidades dos Tratados: Forjando Fronteiras, Elaborando Nações (Bolívia e Brasil: Época Colonial 1967). Goiânia: IX Encontro Internacional da ANPHLAC (Associação de Pesquisadores e Professores de História das Américas), 26 julho a 29 julho de 2010. Disponível em: https://dialnet.unirioja.es/servlet/articulo?codigo=5242455 
SOTOMAYOR, Walter Auad. Relações Brasil Bolívia: a definição das fronteiras. Brasília: Verbena Editora, 2018.

VELHO, Otávio Guilherme. Frentes de expansão e estrutura agrária: estudo do processo de penetração numa área da Transamazônica. Rio de Janeiro: Centro Edelstein de Pesquisas Sociais, 2009. 171p. 